\title{
Evaluation and Management of Sleep Disorders in the Hand Surgery Patient.
}

\author{
Michael P. Gaspar \\ Thomas Jefferson University \\ Patrick M. Kane \\ Thomas Jefferson University \\ Sidney M. Jacoby \\ Thomas Jefferson University \\ Patrick S. Gaspar \\ Harborside Surgical Center
}

\section{A. Lee Osterman \\ Thomas Jefferson University Follow this and additional works at: https://jdc.jefferson.edu/orthofp \\ Part of the Orthopedics Commons, and the Surgery Commons \\ Let us know how access to this document benefits you}

\section{Recommended Citation}

Gaspar, Michael P.; Kane, Patrick M.; Jacoby, Sidney M.; Gaspar, Patrick S.; and Osterman, A. Lee, "Evaluation and Management of Sleep Disorders in the Hand Surgery Patient." (2016).

Department of Orthopaedic Surgery Faculty Papers. Paper 93.

https://jdc.jefferson.edu/orthofp/93

This Article is brought to you for free and open access by the Jefferson Digital Commons. The Jefferson Digital Commons is a service of Thomas Jefferson University's Center for Teaching and Learning (CTL). The Commons is a showcase for Jefferson books and journals, peer-reviewed scholarly publications, unique historical collections from the University archives, and teaching tools. The Jefferson Digital Commons allows researchers and interested readers anywhere in the world to learn about and keep up to date with Jefferson scholarship. This article has been accepted for inclusion in Department of Orthopaedic Surgery Faculty Papers by an authorized administrator of the Jefferson Digital Commons. For more information, please contact: JeffersonDigitalCommons@jefferson.edu. 


\section{Title:}

2 Evaluation and Management of Sleep Disorders in the Hand Surgery Patient

3

4 Running Title:

5 Sleep Disorders in Hand Surgery

\section{Authors and affiliations:}

9 Michael P. Gaspar, MDa

10 michaelpgaspar@gmail.com

Patrick M. Kane, MD

13 pmkkane@gmail.com

Sidney M. Jacoby, MDa

16 smjacoby@handcenters.com

Patrick S. Gaspar, MD

patrickgaspar@yahoo.com

A. Lee Osterman, MDa

alosterman@handcenters.com

a The Philadelphia Hand Center, P.C.

Thomas Jefferson University

Department of Orthopedic Surgery

The Franklin Suite G114

834 Chestnut Street

Philadelphia, PA 19107, USA

b Harborside Surgical Center

33 Department of Anesthesiology

34 Oxon Hill, MD

Corresponding Author:

37 Michael P. Gaspar, MD

38 The Philadelphia Hand Center, P.C.

39 The Franklin Suite G114

40834 Chestnut Street

41 Philadelphia, PA 19107

42 michaelpgaspar@gmail.com

43 (804) 363-9157

44

\section{Key Words:}

47

Insomnia; Sleep Disorders; Hand Surgery; Carpal tunnel syndrome; Obstructive Sleep Apnea 


\section{Abstract}

49 Despite posing a significant public health threat, sleep disorders remain poorly understood

50 and often mismanaged. Though seemingly unrelated, hand surgeons should be particularly

51 mindful of sleep disorders, as numerous conditions of the upper extremity have known

52 associations with sleep disturbances which can adversely affect patient outcomes, function

53 and satisfaction. In addition, patients with sleep disorders are at significantly higher risk

54 for severe, even life-threatening medical co-morbidities, further supporting the important

55 role of hand surgeons in the recognition and management of sleep disorders that are most

56 common in hand surgery. 


\section{Introduction}

59 Sleep disorders are a major public health concern, affecting as many as 70 million adults in

60 the United States alone, while accounting for billions of dollars in financial costs, disability,

61 and even death. [1-5] Sleep disorders are also associated with a myriad of medical

62 conditions including obesity, hypertension, diabetes heart disease, and overall higher

63 mortality risk. [6]

65 Unfortunately, despite these exorbitant socioeconomic and health costs, sleep disorders are 66 often overlooked or improperly treated. [7,8] In hand surgery, numerous conditions have

67 known associations with sleep disorders, and sleep symptoms can directly affect patient outcomes, function and satisfaction. Thus, these disorders are important for hand surgeons to recognize and manage. The purpose of this review is to provide an overview of sleep disorders that are most common in hand surgery, with focus on the preoperative evaluation, and perioperative management of these disorders.

\section{Sleep Disorders in Hand Surgery}

This discussion will focus primarily on two classes of disorders most relevant to hand surgery: (1) dyssomnias which are disorders that produce excessive sleepiness or difficulty in initiating or maintaining sleep and (2) sleep disorders associated with other medical disorders. [9] A more inclusive outline of general sleep disorders is presented in Figure 1.

\section{Intrinsic Dyssomnias}

81 Intrinsic dyssomnias either (a) originate or develop within the body, or (b) arise

82 from causes within the body. [9] This group includes psychological or medical disorders

83 that produce a primary sleep disorder.

Obstructive Sleep Apnea

86 Perhaps the most widely recognized intrinsic dyssomnia in surgical patients is obstructive 87 sleep apnea (OSA). Patients with OSA who are to undergo surgery require specialized management, as these patients are at higher risk for adverse events in the intraoperative 
and postoperative periods. In the perioperative setting, the primary concern is airway management; due to OSA patients' decreased ability to protect their airway, procedures that would otherwise be performed under sedation may require monitored anesthesia care

92 (MAC) or even general anesthesia for. [10,11] Ideally, open communication between the

93 anesthesiologist and the hand surgeon allows these determinations to be made prior to the

94 day of surgery, so as to minimize delays or complications.

95

In addition to patients with a known diagnosis of OSA, surgeons are often tasked with

97 caring for patients who lack a formal diagnosis, despite exhibiting clinical risk factors for OSA. [12] Chung et al reported an alarming $66 \%$ of patients lacking a preoperative OSA diagnosis with difficult intubations were confirmed to have OSA upon further evaluation. [13] Mutter et al found that those patients with undiagnosed OSA were at significantly higher risk of postoperative cardiac arrest than confirmed OSA patients, and that both

102 groups faired worse than non-OSA patients. [14] These studies together point out the 103 importance for the hand surgeon to recognize and screen for OSA, which can be done 104 utilizing validated OSA screening methods, such as the STOP-Bang questionnaire (Table 1).

105 Surgeons should also have a low threshold for referring patients with positive findings on 106 OSA screening for further evaluation. [13,15] Postoperative management of OSA patients is 107 also critical in avoiding morbidity, and OSA patients should resume continuous- or bilevel 108 positive-airway-pressure (CPAP or BiPAP) treatment as soon as they are able. [15]

109 Postoperative pain control regimens in OSA patients also merit special attention, which will 110 be discussed shortly.

\section{Extrinsic Dyssomnias}

113 Extrinsic dyssomnias are those that originate or develop from causes outside of the body.

114 [9] External factors are necessary to produce these disorders, and their removal is often 115 therapeutic to the sleep disturbance. [9] In hand surgery, these most notably include both 116 drug-induced and drug-dependant sleep disorders. 
Opioid-Induced Sleep Disorders

119 A true understanding of the complex interplay of pain, opioid medication, and sleep

120 disturbance remains elusive. Although evidence shows that pain and sleep exhibit a

121 circular relationship with one another (i.e. pain causes sleep disturbance and sleep

122 disturbance intensifies pain), [16-19] opioids used to concomitantly treat both pain and

123 secondary sleep disorders are not always successful. [20,21]

Opioid receptors in the brain are located in the same nuclei that are active in sleep regulation and abnormal sleep architecture has been reported as a characteristic feature of opioid use, with a reduction of rapid eye movement (REM), slow wave sleep stages, and

128 overall sleep quality. [18,20,22] Opioid use in OSA patients can be particularly

129 troublesome, as opioids not only impair arousal, but can worsen airway obstruction, even

130 in non-OSA patients. [21,23,24] Thus, alternative multimodal pain management

131 approaches are recommended to minimize the need for opioids for OSA patients. These

132 include: regional or local anesthesia when appropriate, continuous peripheral nerve

133 blockade, and non-opioid analgesics such as acetaminophen and NSAIDS. [15,23,25-27]

134 Recent evidence also supports use of low-dose ketamine or adjuvant clonidine injections

135 to potentiate local or regional nerve blocks. [23,28,29] Finally, conservative measures

136 aimed at decreasing postoperative pain and inflammation such as icing, elevation, and

137 compression should be emphasized, especially upon discharge home.

\section{Sedative-Dependent Sleep Disorders}

140 The use of short-acting sedative-hypnotics, particularly non-benzodiazepine sedative

141 hypnotics (NBSH, e.g. zolpidem), for treatment of insomnia has increased markedly in

142 recent decades. [30] Generally intended to treat short-term insomnia, NBSH

143 discontinuation may precipitate rebound insomnia, lasting up to weeks in extreme cases, or

144 after taking a single dose. [31-33] Thus, the dependency potential is relatively high. [34-36]

145 Use of zolpidem as a postoperative sleep aid or pain-adjuvant has recently been described

146 following knee and shoulder surgery with reported success in improving sleep quality and

147 function, while decreasing opioid requirements, pain and fatigue. [37-39] However, none of 148 these studies reported patient outcomes beyond the acute treatment period. [37-39] Its 
similar utility in hand surgery has not been reported. Perhaps surprisingly, antihistamines

150 used as sleep aids may warrant similar caution. [41] A recent survey of patients who took

151 the commonly-used sedative $\mathrm{H} 1$ antihistamine doxylamine found the majority of patients

152 used the medication daily for at least six months, including $77 \%$ who experienced rebound 153 insomnia when attempting to discontinue use. [41] These findings suggest that sedative

154 hypnotics and antihistamines should be used with judiciously in hand surgery patients 155 with sleep disorders.

\section{Sleep Disorders Associated with Mental, Neurologic, or Other Medical Disorders}

158 This second category includes a variety primary medical disorders that secondarily involve 159 sleep disturbance or excessive sleepiness as a major clinical feature, [9] including several

160 hand and upper extremity conditions.

\section{Carpal Tunnel Syndrome}

163 Insomnia is a nearly universal finding in patients with carpal tunnel syndrome (CTS), often

164 serving as the primary motivating factor for seeking surgical care. [42-48] Although the 165 mechanism linking these two conditions is unclear, McCabe and colleagues reported that patients with CTS are more likely to prefer sleeping on their side compared to control patients. [42-44] The authors acknowledge, however, that these associative findings do not necessary prove causation. In an effort to further characterize the severity of sleep disturbance in CTS patients, Patel et al prospectively studied patients with CTS and found that $78 \%$ of patients met the threshold for poor sleep quality using the Pittsburgh Sleep Quality Index (PSQI), a validated sleep-quality outcome measure. [46,49,50] The authors

172 also noted a positive correlation between CTS-related functional impairment and severity

173 of sleep symptoms. [46] The authors did not study the potential association of preoperative

174 electrodiagnostic findings with sleep symptom severity, nor did they investigate the

175 potential therapeutic effect of median nerve decompression on sleep symptoms. Both of

176 these associations may warrant further study, as the ability to predict relief of sleep

177 symptoms following decompressive surgery would allow clinicians to better tailor

178 management for CTS patients whose primary complaints are sleep-related. 
181 Sleep disturbances in patients with Rheumatoid Arthritis (RA) are multifactorial, 182 codependent on pain, fatigue, and depression. [51-53] In a prospective analysis of RA 183 patients seen at an outpatient clinic, Løppenthin et al reported that $61 \%$ met criteria for 184 poor sleep using the PSQI. [52] Westhovens et al found that RA disease activity showed 185 significantly positive correlation with worsening sleep symptoms, [53] while Fragiadaki et

186 al reported improvement in sleep symptoms in a series of 15 RA patients treated with 187 tocilizumab, [54] together suggesting that primary management of underlying RA activity 188 may serve as an optimal strategy for co-managing sleep symptoms. Recent evidence has 189 also demonstrated a significant association between psoriatic arthritis and sleep disorders, particularly OSA and insomnia. [55-58] Although etanercept was reported to improve insomnia symptoms in patients with psoriatic arthritis, treatment with adalimumab did not show a therapeutic effect on patients' OSA symptoms. [57,58] Patients with both psoriatic

193 arthritis and OSA who are to undergo hand surgery should be managed according to the OSA principles discussed earlier.

\section{Additional Management Considerations}

198 Given the potential adverse effects associated with sedatives and opioid pain medication,

199 alternative treatment modalities for concomitant sleep disturbance and acute postoperative pain warrant further discussion. Gamma-aminobutyric acid (GABA) analogues gabapentin and pregabalin may have utility for treating concomitant pain and sleep symptoms, either as primary therapeutic or adjuvant agents. [59,60] Gabapentin has

203 previously been shown as an effective treatment for both pain and sleep disturbance in CTS 204 patients, [61] although this finding has been both supported and refuted in more recent 205 studies. $[62,63]$ Pregabalin shows promise in the concomitant treatment of sleep and pain symptoms, albeit in patients with fibromyalgia, for which it is FDA-approved. [64,65] While neither medication is currently FDA-approved for neuropathic pain associated specifically with conditions of the upper extremity, further investigation to that end could be worthwhile. [59] 
211 Another promising agent for use in hand surgery is exogenous melatonin. Although its

212 sleep-promoting characteristics are widely-reported, melatonin possesses numerous

213 additional benefits which suggest an ideal role as a therapeutic agent in hand surgery. [66]

214 In vitro studies on chondrocytes demonstrate that melatonin is chondrogenic and

215 promotes matrix synthesis, and can also serve as a rescue agent for chondrocytes that are

216 exposed to damaging pro-inflammatory or cytotoxic factors. [67-69] In an animal model of

217 median nerve injury, sleep deprivation made rats more vulnerable to nerve injury-induced

218 neuropathic pain, while melatonin reversed nerve injury-induced hypersensitivity. [70] In

219 the lone clinical study evaluating its efficacy in hand surgery, melatonin was found to

220 improve tourniquet tolerance while decreasing opioid requirement in patients receiving

221 regional anesthesia intravenously. [71] Given this therapeutic potential and limited

222 adverse effect profile, use of melatonin in hand surgery certainly warrants ongoing trial

223 and further investigation.

\section{Current Limitations and Future Directions}

227 Due to the complex interplay of sleep with pain, psychiatric disorders, social factors, and 228 other associated conditions, the evaluation of sleep disorders in the hand surgery patient is 229 rarely straightforward. In a recent study by Peters and colleagues, the authors attempted 230 to determine a relationship between sleep disturbance and upper-extremity disability, and 231 found that psychological factors such as ineffective coping strategies were more likely to 232 predict arm disability than sleep symptoms. [72] The authors discussed the possibility that 233 sleep disturbance was also the product of these psychological factors, suggesting a

234 bidirectional relationship. Their study exemplifies the challenging nature inherent to 235 determining underlying pathology and causal relationships regarding sleep disturbances.

236 This is echoed by Shulman et al, who found that sleep disturbance following distal radius 237 fracture at long-term follow-up was more dependent on mental health than on functional 238 status. [73]

240 A second limitation of the current evidence regarding sleep disorders in hand surgery is 241 with respect to the heterogeneity of the patient populations studied; a shortcoming fully 
242 acknowledged by Peters and colleagues. [72] In their study fractures, soft-tissue injuries, 243 and degenerative conditions were all treated as equivalent upper extremity disabilities.

244 Furthermore, CTS and cubital tunnel syndrome were lumped together although there is no 245 current literature that describes sleep disorders in patients with cubital tunnel syndrome.

246 Similarly, in their study of melatonin's utility in improving tourniquet tolerance and

247 decreasing opioid requirements, Mowafi and Ismail did not stratify or match patients based

248 on condition or procedure. [71] Future studies using larger, more homogenous patient

249 cohorts, would be critical to fully understanding the relationships between sleep disorders

250 and hand pathologies, and developing precise and effective regimens to treat coexisting

251 sleep and hand disease.

252

253

254 


\section{References}

1. Hillman DR, Murphy AS, Pezzullo L. The economic cost of sleep disorders. Sleep. 2006 Mar;29(3):299-305.

2. Daley M, Morin CM, LeBlanc M, Grégoire JP, Savard J, Baillargeon L. Insomnia and its relationship to health-care utilization, work absenteeism, productivity and accidents.

3. Daley M, Morin CM, LeBlanc M, Grégoire JP, Savard J. The economic burden of insomnia: direct and indirect costs for individuals with insomnia syndrome, insomnia symptoms, and good sleepers. Sleep. 2009 Jan;32(1):55-64. Sleep Med. 2009 Apr;10(4):427-38.

4. Hossain JL, Shapiro CM. The prevalence, cost implications, and management of sleep disorders: an overview. Sleep Breath. 2002 Jun;6(2):85-102.

7. Ohayon MM. Epidemiology of insomnia: what we know and what we still need to learn. Sleep Med Rev. 2002;6:97-111.

5. Léger D, Bayon V. Societal costs of insomnia. Sleep Med Rev. 2010 Dec;14(6):379-89.

6. Taylor DJ, Mallory LJ, Lichstein KL, Duurence HH, Riedel BW, Bush AJ. Comorbidity of chronic insomnia with medical problems. Sleep. 2007;30(2):213-218.

9. American Academy of Sleep Medicine (AASM). The International Classification of Sleep

8. Wittchen HU, Krause P, Hofler M, Pittrow D, Winter S, Spiegel B, et al. NISAS-2000: the "nationwide insomnia screening and awareness study". Prevalence and interventions in primary care. Fortschr Med Orig. 2001;119:9-19.

$$
\text { Disorders: 2nd Edition. Westchester, IL: American Academy of Sleep Medicine; } 2005 .
$$


10. LaPorte D, Vallera C. Sedation for Hand Surgery in Adults. J Hand Surg Am. 2011;36(7):1231-1233.

11. Vallera C, LaPorte D. Monitored Anesthesia Care for Hand Surgery in Adults. J Hand Surg Am. 2011;36(7):1235-1236.

12. Kaw R, Michota F, Jaffer A, Ghamande S, Auckley D, Golish J. Unrecognized Sleep Apnea in the Surgical Patient. Chest. 2006;129(1):198-205.

13. Chung F, Yegneswaran B, Herrera F, Shenderey A, Shapiro C. Patients with Difficult Intubation May Need Referral to Sleep Clinics. Anesth Analg. 2008;107(3):915-920.

14. Mutter TC, Chateau D, Moffatt M, Ramsey C, Roos LL, Kryger M. A matched cohort study of postoperative outcomes in obstructive sleep apnea: could preoperative diagnosis and treatment prevent complications? Anesthesiology. 2014 Oct;121(4):707-18.

17. Kundermann B, Krieg JC, Schreiber W, Lautenbacher S. The effect of sleep deprivation

18. Onen SH, Onen F, Courpron P, Dubray C. How pain and analgesics disturb sleep. Clin J Pain. 2005;21:422-31.

16. Brennan MJ, Lieberman JA 3rd. Sleep disturbances in patients with chronic pain: effectively managing opioid analgesia to improve outcomes. Curr Med Res Opin. 2009; 25: 1045-55. on pain. Pain Res Manag 2004;9:25-32. 
Forward. J Pain. 2013;14(12):1539-1552.

20. Wang D, Teichtahl H. Opioids, sleep architecture and sleep disordered breathing. Sleep Med Rev. 2007; 11: 35-46.

21. Yue HJ, Guilleminault G. Opioid medication and sleep-disordered breathing. Med Clin North Am. 2010; 94: 435-46.

22. Dinsdale J, Norman D, DeJardin D, et al. The effect of opioids on sleep architecture. J Clin Sleep Med. 2007; 3: 33-6.

24. Arora N, Cao M, Javaheri S. Opioids, Sedatives, and Sleep Hypoventilation. Sleep Med Clin. 2014;9(3):391-398.

23. Mulier JP. Perioperative opioids aggravate obstructive breathing in sleep apnea syndrome: mechanisms and alternative anesthesia strategies. Curr Opin Anaesthesiol. 2016 Feb;29(1):129-33.

25. Lalonde D. Minimally invasive anesthesia in wide awake hand surgery. Hand Clin. 2014 Feb;30(1):1-6.

26. Fingerman M. Regional Anesthesia for Outpatient Hand Surgery: Ultrasound-Guided Peripheral Nerve Block. J Hand Surg Am. 2011;36(3):532-534.

27. Richman J, Liu S, Courpas G et al. Does Continuous Peripheral Nerve Block Provide Superior Pain Control to Opioids? A Meta-Analysis. Anesthesia \& Analgesia. 
29. Kaur S, Saroa R, Aggarwal S. Effect of intraoperative infusion of low-dose ketamine on management of postoperative analgesia. J Nat Sci Biol Med. 2015; 6:378-382.

30. Moloney M, Konrad T, Zimmer C. The Medicalization of Sleeplessness: A Public Health Concern. Am J Public Health. 2011;101(8):1429-1433.

31. Mendelson WB, Jain B. An assessment of short-acting hypnotics. Drug Saf. 1995 Oct;13(4):257-70.

32. Kales A, Manfredi RL, Vgontzas AN, Bixler EO, Vela-Bueno A, Fee EC. Rebound insomnia after only brief and intermittent use of rapidly eliminated benzodiazepines. Clin Pharmacol Ther. 1991 Apr;49(4):468-76.

33. Monti JM, Attali P, Monti D, Zipfel A, de la Giclais B, Morselli PL. Zolpidem and rebound insomnia--a double-blind, controlled polysomnographic study in chronic insomniac patients. Pharmacopsychiatry. 1994 Jul;27(4):166-75.

34. Victorri-Vigneau C, Gérardin M, Rousselet M, Guerlais M, Grall-Bronnec M, Jolliet P. An update on zolpidem abuse and dependence. J Addict Dis. 2014;33(1):15-23.

35. Victorri-Vigneau C, Dailly E, Veyrac G, Jolliet P. Evidence of zolpidem abuse and dependence: results of the French Centre for Evaluation and Information on Pharmacodependence (CEIP) network survey. Br J Clin Pharmacol. 2007 Aug;64(2):198-209.

36. Manthey L, Lohbeck M, Giltay EJ, van Veena T, Zitman FG, Penninx BW. Correlates of benzodiazepine dependence in the Netherlands Study of Depression and Anxiety. Addiction. 2012 Dec;107(12):2173-82.

37. Tompkins M, Plante M, Monchik K, Fleming B, Fadale P. The use of a nonbenzodiazepine hypnotic sleep-aid (Zolpidem) in patients undergoing ACL 
reconstruction: a randomized controlled clinical trial. Knee Surg Sports Traumatol Arthrosc. 2011 May;19(5):787-91.

38. Gong L, Wang Z, Fan D. Sleep Quality Effects Recovery After Total Knee Arthroplasty (TKA)--A Randomized, Double-Blind, Controlled Study. J Arthroplasty. 2015 Nov;30(11):1897-901.

39. Cho CH, Lee SW, Lee YK, Shin HK, Hwang I. Effect of a sleep aid in analgesia after arthroscopic rotator cuff repair. Yonsei Med J. 2015 May;56(3):772-7.

40. Chung SD, Lin CC, Wang LH, Lin HC, Kang JH. Zolpidem Use and the Risk of Injury: A Population-Based Follow-Up Study. PLoS One. 2013 Jun 27;8(6):e67459.

41. Roussin A, Bouyssi A, Pouché L, Pourcel L, Lapeyre-Mestre M. Misuse and dependence on non-prescription codeine analgesics or sedative $\mathrm{H} 1$ antihistamines by adults: a

42. McCabe S, Uebele A, Pihur V, Rosales R, Atroshi I. Epidemiologic Associations of Carpal Tunnel Syndrome and Sleep Position: Is There a Case for Causation?. HAND. cross- sectional investigation in France. PLoS One. 2013 Oct 3;8(10):e76499.

44. McCabe S, Gupta A, Tate D, Myers J. Preferred sleep position on the side is associated

43. McCabe S, Xue Y. Evaluation of sleep position as a potential cause of carpal tunnel tunnel syndrome. HAND. 2011;7(1):55-58. 
46. Patel A, Culbertson M, Patel A et al. The Negative Effect of Carpal Tunnel Syndrome on Sleep Quality. Sleep Disorders. 2014;2014:1-7.

413 47. Becker S, Makanji H, Ring D. Expected and Actual Improvement of Symptoms With

414 Carpal Tunnel Release. J Hand Surg Am. 2012;37(7):1324-1329.e5.

48. Kadzielski J, Malhotra L, Zurakowski D, Lee S, Jupiter J, Ring D. Evaluation of Preoperative Expectations and Patient Satisfaction After Carpal Tunnel Release. J Hand Surg Am. 2008;33(10):1783-1788.

49. Buysse DJ, Reynolds CF, Monk TH, Berman SR, Kupfer DJ. The Pittsburgh Sleep Quality Index: a new instrument for psychiatric practice and research. Psychiatry Res 1989;28:193-213.

50. Mollayeva T, Thurairajah P, Burton K, Mollayeva S, Shapiro CM, Colantonio A. The Pittsburgh sleep quality index as a screening tool for sleep dysfunction in clinical and non-clinical samples: A systematic review and meta-analysis. Sleep Med Rev. 2016 Feb;25:52-73.

51. Luyster FS, Chasens ER, Wasko MC, Dunbar-Jacob J. Sleep quality and functional

52. Løppenthin K, Esbensen BA, Jennum P, Østergaard M, Tolver A, Thomsen T, Midtgaard J.

53. Westhovens R, Van der Elst K, Matthys A, Tran M, Gilloteau I. Sleep problems in patients with rheumatoid arthritis. J Rheumatol. 2014 Jan;41(1):31-40. 
54. Fragiadaki K, Tektonidou MG, Konsta M, Chrousos GP, Sfikakis PP. Sleep disturbances and interleukin 6 receptor inhibition in rheumatoid arthritis. J Rheumatol. 2012;39:602.

55. Gupta MA, Simpson FC, Gupta AK. Psoriasis and sleep disorders: A systematic review.

56. Egeberg A, Khalid U, Gislason GH, Mallbris L, Skov L, Hansen PR. Psoriasis and Sleep Sleep Med Rev. 2015 Sep 21;29:63-75. Apnea: A Danish Nationwide Cohort Study. J Clin Sleep Med. 2015 Dec 22.

57. Tyring S, Gottlieb A, Papp K, Gordon K, Leonardi C, Wang A, et al. Etanercept and clinical outcomes, fatigue, and depression in psoriasis: double-blind placebo-controlled randomised phase III trial. Lancet 2006;367:29e35.

59. Brunton L, Laporte D. Use of Gabapentin and Pregabalin for Hand Surgery Patients. J Hand Surg Am. 2012;37(7):1486-1488.

60. de la Calle JL, De Andres J, Pérez M, López V. Add-on treatment with pregabalin for 467

58. Maari C, Bolduc C, Nigen S, Marchessault P, Bissonnette R. Effect of adalimumab on sleep parameters in patients with psoriasis and obstructive sleep apnea: a randomized controlled trial. J Dermatol Treat. 2014;25:57e60.

patients with uncontrolled neuropathic pain who have been referred to pain clinics. Clin Drug Investig. 2014 Dec;34(12):833-44.

61. Duman I, Aydemir K, Ozgul A, Kalyon TA. Assessment of the efficacy of gabapentin in carpal tunnel syndrome. J Clin Rheumatol. 2008 Jun;14(3):175-7.

62. Eftekharsadat B, Babaei-Ghazani A, Habibzadeh A. The Efficacy of 100 and $300 \mathrm{mg}$ Gabapentin in the Treatment of Carpal Tunnel Syndrome. Iran J Pharm Res. 2015 Fall;14(4):1275-80. 
472 63. Hui AC, Wong SM, Leung HW, Man BL, Yu E, Wong LK. Gabapentin for the treatment of

473 carpal tunnel syndrome: a randomized controlled trial. Eur J Neurol. 2011

474 May;18(5):726-30.

64. Roth T, Lankford DA, Bhadra P, Whalen E, Resnick EM. Effect of pregabalin on sleep in patients with fibromyalgia and sleep maintenance disturbance: a randomized, placebo-

65. Roth T, Bhadra-Brown P, Pitman VW, Resnick EM. Pregabalin Improves FibromyalgiaRelated Sleep Disturbance. Clin J Pain. 2015 May 28.

66. Landis CA. Is Melatonin the Next "New" Therapy to Improve Sleep and Reduce Pain? Sleep. 2014;37(9):1405-1406.

67. Lim H-D, Kim Y-S, Ko S-H, et al. Cytoprotective and anti-inflammatory effects of melatonin in hydrogen peroxide-stimulated CHON-001 human chondrocyte cell line and rabbit model of osteoarthritis via the SIRT1 pathway. J Pineal Res. 2012;53(3):225237.

68. Liu X, Xu Y, Chen S, et al. Rescue of proinflammatory cytokine-inhibited chondrogenesis articular chondrocytes. J Pineal Res. 2009;46(2):181-187. 
500 70. Huang C-T, Chiang RP-Y, Chen C-L, Tsai Y-J. Sleep deprivation aggravates median nerve 501 injury-induced neuropathic pain and enhances microglial activation by suppressing 502 melatonin secretion. Sleep. 2014;37(9):1513-1523.

503

504 71. Mowafi HA, Ismail SA. Melatonin improves tourniquet tolerance and enhances

505 postoperative analgesia in patients receiving intravenous regional anesthesia. Anesth

$506 \quad$ Analg. 2008;107(4):1422-1426.

507

508 72. Peters RM, Menendez ME, Mellema JJ, Ring D, Vranceanu AM. Sleep Disturbance and 509 Upper-Extremity Disability. Arch Bone Jt Surg. 2016 Jan;4(1):35-40.

510

511 73. Shulman BS, Liporace FA, Davidovitch RI, Karia R, Egol KA. Sleep disturbance after

512 fracture is related to emotional well-being rather than functional result. J Orthop

513 Trauma. 2015 Mar;29(3):e146-50.

514

515

516

517

518

519

520 
521 Figure 1. Flow chart outlining the key types of sleep disorders relative to hand surgery in 522 the context of a broader overview of all sleep disorder categories. The first level represents 523 the three main categories of sleep disorders. Note that boxes in grey are not relevant to this 524 discussion, those in red highlight the key types of sleep disorders known to be related to 525 hand surgery patients, and those in purple represent conditions that are likely to be 526 associated with sleep disorders based on current evidence.

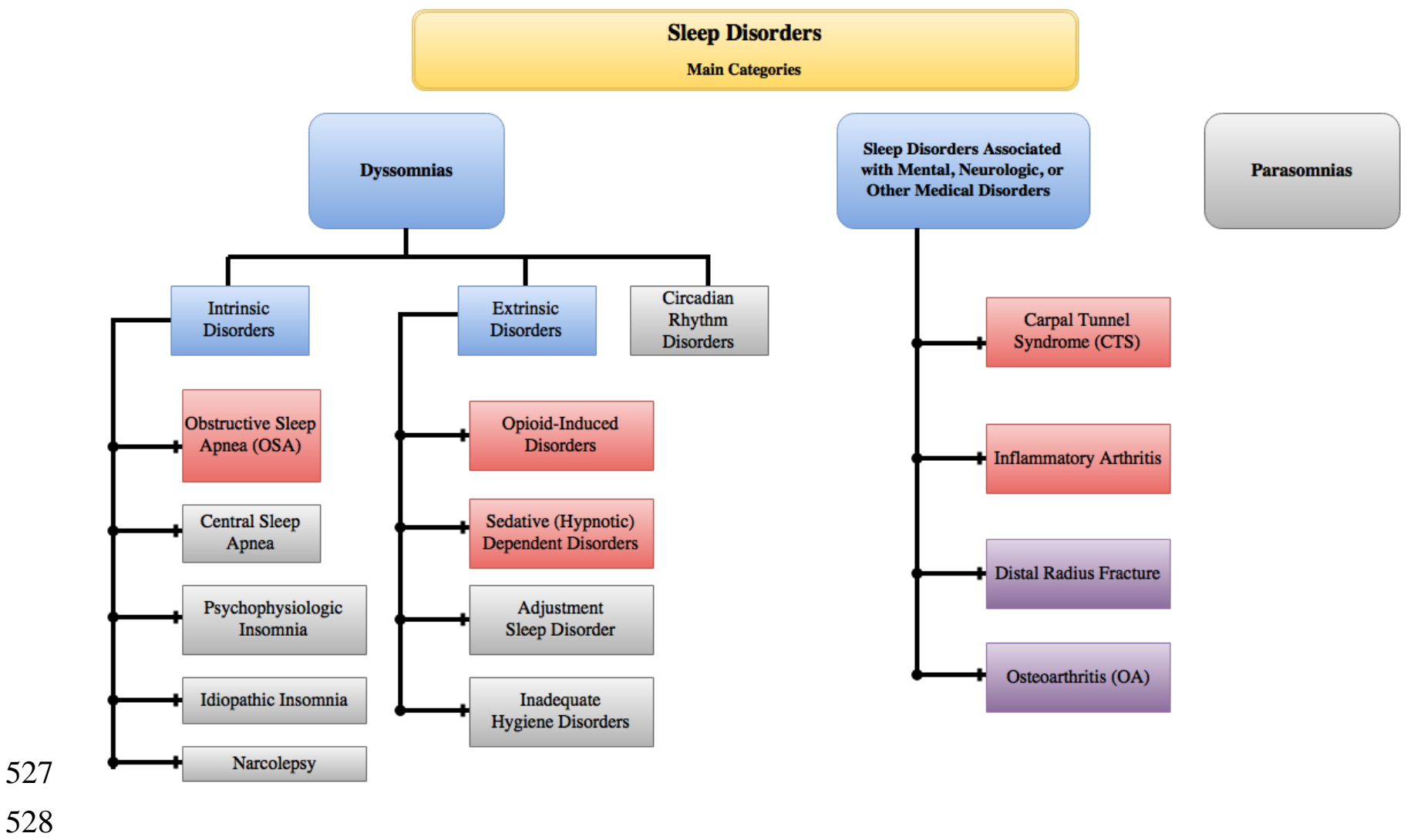


530 Table 1. STOP-BANG Questionnaire to assess for risk of Obstructive Sleep Apnea (OSA).

531 The first section (STOP) consists of four history or symptom-related questions for the

532 patient to answer, while the second section (BANG) consists of four items that may be

533 objectively measured by the clinician. Answers of "Yes" to any question or measure results

534 in a point, while "No" does not result in a point. Patients with total scores of 0-2, 3-4 and 5-

5358 points are considered low, intermediate, and high risk of having OSA, respectively.

536

\begin{tabular}{|l|c|c|}
\hline \multicolumn{1}{|c|}{ Question or Variable } & YES & NO \\
\hline \multicolumn{1}{|c|}{ STOP } & & \\
\hline $\begin{array}{l}\text { Do you SNORE loudly } \\
\text { (louder than talking or loud enough to be heard through closed doors)? }\end{array}$ & 1 & 0 \\
\hline Do you often feel TIRED, fatigued, or sleepy during daytime? & 1 & 0 \\
\hline Has anyone OBSERVED you stop breathing during your sleep? & 1 & 0 \\
\hline Do you have or are you being treated for high blood PRESSURE? & 1 & 0 \\
\hline BANG & & 1 \\
\hline BMI more than 35kg/m2? $\quad 1$ & 0 \\
\hline AGE over 50 years old? & 1 & 0 \\
\hline NECK circumference > 16 inches (40cm)? & 1 & 0 \\
\hline GENDER: Male? & 1 \\
\hline
\end{tabular}

